\title{
Patients' Perspectives of Oral and Injectable Type 2 Diabetes Medicines, Their Body Weight and Medicine- Taking Behavior in the UK: A Systematic Review and Meta-Ethnography
}

\author{
Aikaterini Psarou (D) $\cdot$ Helen Cooper · John P. H. Wilding
}

Received: June 21, 2018 / Published online: August 17, 2018

(C) The Author(s) 2018

\section{ABSTRACT}

The aim of this review is to identify peoples' perspectives of their glucose-lowering and antiobesity drugs in relation to diabetes and weight control and to explore how these views affect medication adherence. Theoretical perspectives associated with medicine-taking behavior are also explored. The systematic review was based on a meta-ethnography of qualitative studies identified through a search of 12 medical and social science databases and subsequent citation searches. The quality of all studies was assessed. Sixteen studies were included with data from 360 UK individuals. No relevant studies were identified which focused on anti-obesity and

Enhanced Digital Features To view enhanced digital features for this article go to https://doi.org/10.6084/ m9.figshare.6949055.

Electronic supplementary material The online version of this article (https://doi.org/10.1007/s13300018-0490-5) contains supplementary material, which is available to authorized users.

A. Psarou $(\bowtie) \cdot J$. P. H. Wilding Obesity and Endocrinology Research, Institute of Ageing and Chronic Disease, University of

Liverpool, Liverpool, UK

e-mail: kpsarou@yahoo.co.uk

H. Cooper

Faculty of Health and Social Care, Department of Public Health and Wellbeing, University of Chester, Chester, UK non-insulin injectable drugs. The review revealed that the patients' perspectives and emotional state were influenced by starting and/or changing to a new glucose-lowering medicine. These were also influenced by prior medication experience, disease perceptions and interactions with clinicians. Despite reports of positive experiences with and positive perceptions of medicines, and of participation in strategies to regain life control, medication non-adherence was common. Accepting glucose-lowering medicines impacted on the individual's perception of lifestyle changes, and it was notable that weight loss was not perceived as a strategy to support diabetes management. Synthesis revealed that more than one theory is required to explain medicine-taking behavior. New insights into the underlying factors of poor adherence and the specific practical issues identified in this review can help in the development of patient-centered interventions.

Funding: Diabetes UK.

Keywords: Medication adherence; Metaethnography; Patient perspectives; Systematic review; Type 2 diabetes medicines; Weight loss

\section{INTRODUCTION}

Type 2 Diabetes mellitus (T2DM) is a major global public health problem, with over $80 \%$ of 
this population in the UK being either overweight or obese [1]. Long-term hyperglycemia (glycated hemoglobin [HbA1c] $>8.0 \%$, $64 \mathrm{mmol} / \mathrm{mol}$ ) and weight gain increase the risk of disabling secondary complications. Therefore, body weight and glycemic control are important targets in managing T2DM [2].

Despite the availability and effectiveness of glucose-lowering and anti-obesity drugs (GLDs and AODs, respectively) systematic reviews show that patients with T2DM rarely adhere to their medication [3-5], and currently there are no effective interventions that consistently support and improve adherence in this group of patients [6-8]. The term "adherence" is used in this review, but due to the absence of a universally acceptable standardized definition in the literature $[9,10]$, its use can be problematic. Here we focus on the extent to which patients intentionally or unintentionally adhere to their medication as prescribed. Medicine-taking behavior among diabetes patients is complex and multifactorial [10-12], while patterns of adherence can be determined as early as at the point of prescription [11]. Medication non-adherence has implications for patients as it may mean a lost opportunity for health gain [13] or more rapid disease progression which risks further intensive medical intervention, alongside the financial burdens this can impose on healthcare budgets.

An abundance of research and systematic reviews have explored the perception of medicines or medication adherence in people with diabetes, yet these lack a sole focus on T2DM medicines and methodological rigor and are diverse in terms of study design, population and settings [14-24]. Healthcare systems across and within countries vary in their diabetes care delivery, particularly regarding HbA1c targets, availability and/or licences of prescribed drugs, the use of which is also influenced by guidelines and cost. The UK is one of the few countries where people with diabetes are exempt from all prescription charges [25].

The aim of this systematic review is to identify the perspectives of UK patients regarding their T2DM medicines (GLDs and AODs) and to determine how these perspectives influence adherence. As the array of T2DM medicines has increased over the last few years, many of which have potential for both weight loss and diabetes control, in either oral or injectable form, in this review we explore whether the medicine's effect on diabetes and body weight affected the perspectives and adherence of patients. People with T2DM experience many changes in diabetes medications over a lifetime of diabetes and, therefore, in this review we also focus on whether patients' views change over time or between treatment changes. A secondary objective was to identify the optimal research designs and theoretical perspectives for studying beliefs, attitudes and medicine-taking behaviors in this patient population.

\section{METHODS}

Noblit and Hare's meta-ethnographic approach [26] using the seven-steps method (Fig. 1) was used in this review. Highly relevant subsequent adaptations to this approach related to medicine-taking and/or diabetes management $[14,27,28]$ also informed the methodology. The review is based on previously conducted studies and does not involve any new studies of human or animal subjects performed by any of the authors.

\section{Search Strategy}

Electronic databases (Cochrane Library, DARE/ CRD/NHS (via http://www.crd.york.ac.uk), PROSPERO, Web of Science, SCOPUS, ScienceDirect, PsychINFO, CINAHL Plus, MEDLINE, EMBASE, AMED, EBSCO) were searched from inception to February 2016 (full strategy is shown in the Electronic Supplementary Material $[\mathrm{ESM}])$. A broad and specific approach was used to identify studies based on a combination of the following search terms: "type 2 diabetes," "medication-taking," "adherence," "compliance," "treatment," "medication," "oral hypoglycemic drugs/agents," "anti-obesity drugs," "insulin," "beliefs," "attitudes" and "weight." The references of all retrieved articles were checked for relevant studies. 


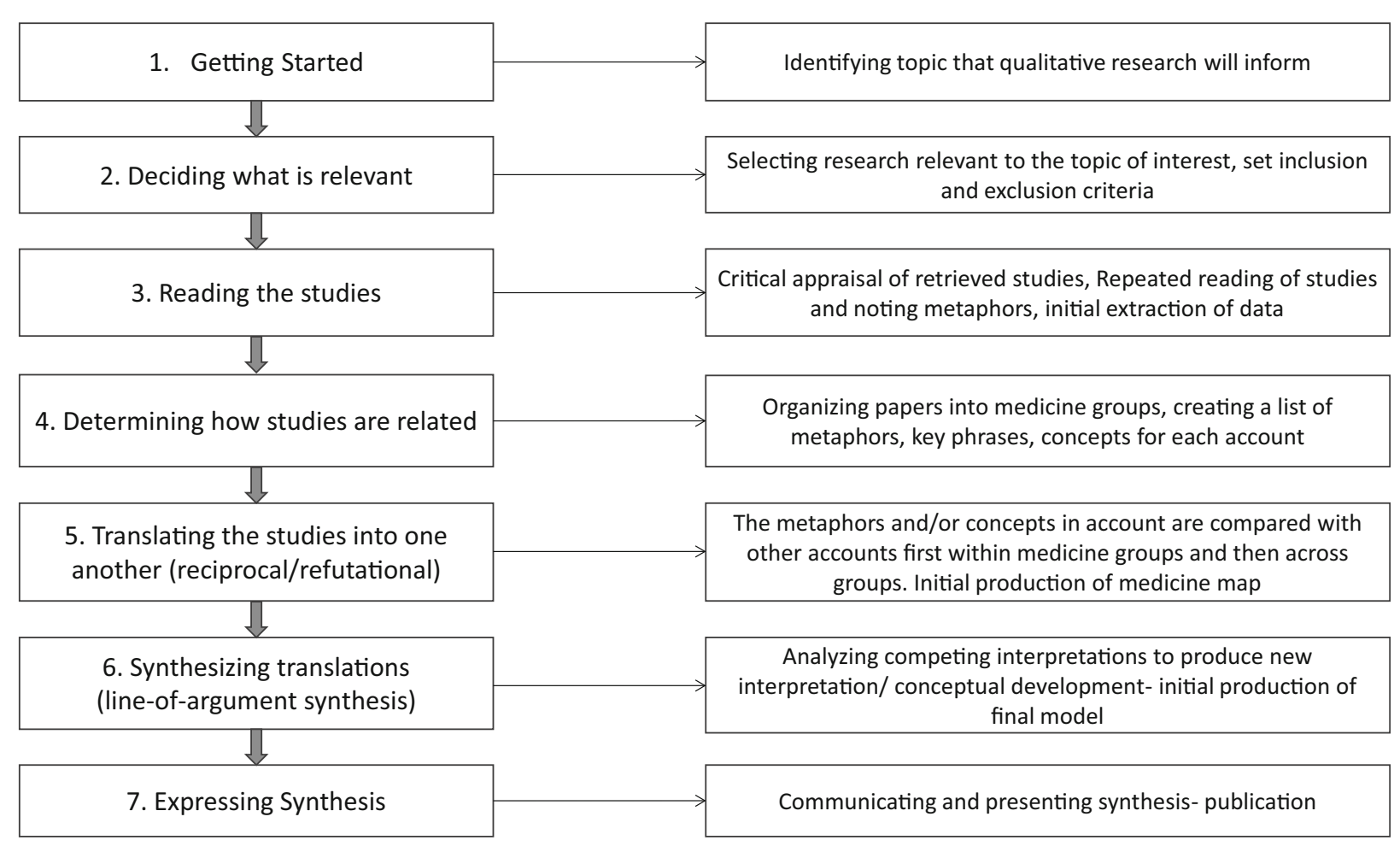

Fig. 1 Seven-step meta-ethnography [26]

\section{Study Selection}

Published studies in English in which the methodology included a qualitative data collection and analysis with a primary focus on medication-taking behavior or beliefs/attitudes towards GLDs and/or AODs were included in the review. Mixed-method studies reporting qualitative data were also included. Studies were selected if the participants were (1) adults (> 18 years) with T2DM, (2) using pharmacotherapy to manage diabetes and/or weight and (3) managed in the UK (primary care or an outpatient clinic in secondary care). Studies were excluded if participants had gestational diabetes or were hospitalized, or they included all types of diabetes and types of therapies but did not focus on the above criteria in a subgroup analysis. The lead author (AP) performed the systematic literature search, of which a sample was verified by the second author (HC). This process involved screening papers by title, abstract and full text. Discrepancies were resolved through consensus. A further three studies were identified following screening of individual studies from two systematic reviews $[20,24]$ as they were eligible for this review. The review followed the Preferred Reporting Items for Systematic Reviews and Meta-Analysis (PRISMA) checklist for the selection of studies (Fig. 2).

\section{Quality Assessment}

Included studies were assessed for quality using the Critical Appraisal Skills Program (CASP) criteria for qualitative research [29], with an additional question regarding each study's theoretical perspective, as illustrated elsewhere [30]. To ensure rigor (see ESM), articles were included only if they scored $\geq 7$ (maximum score 11), resulting in one article being excluded at this stage (Fig. 2). One author (AP) critically appraised all studies, and a sub-sample was checked by a second author (HC). Both AP and HC examined papers with low CASP score to reach a consensus. 


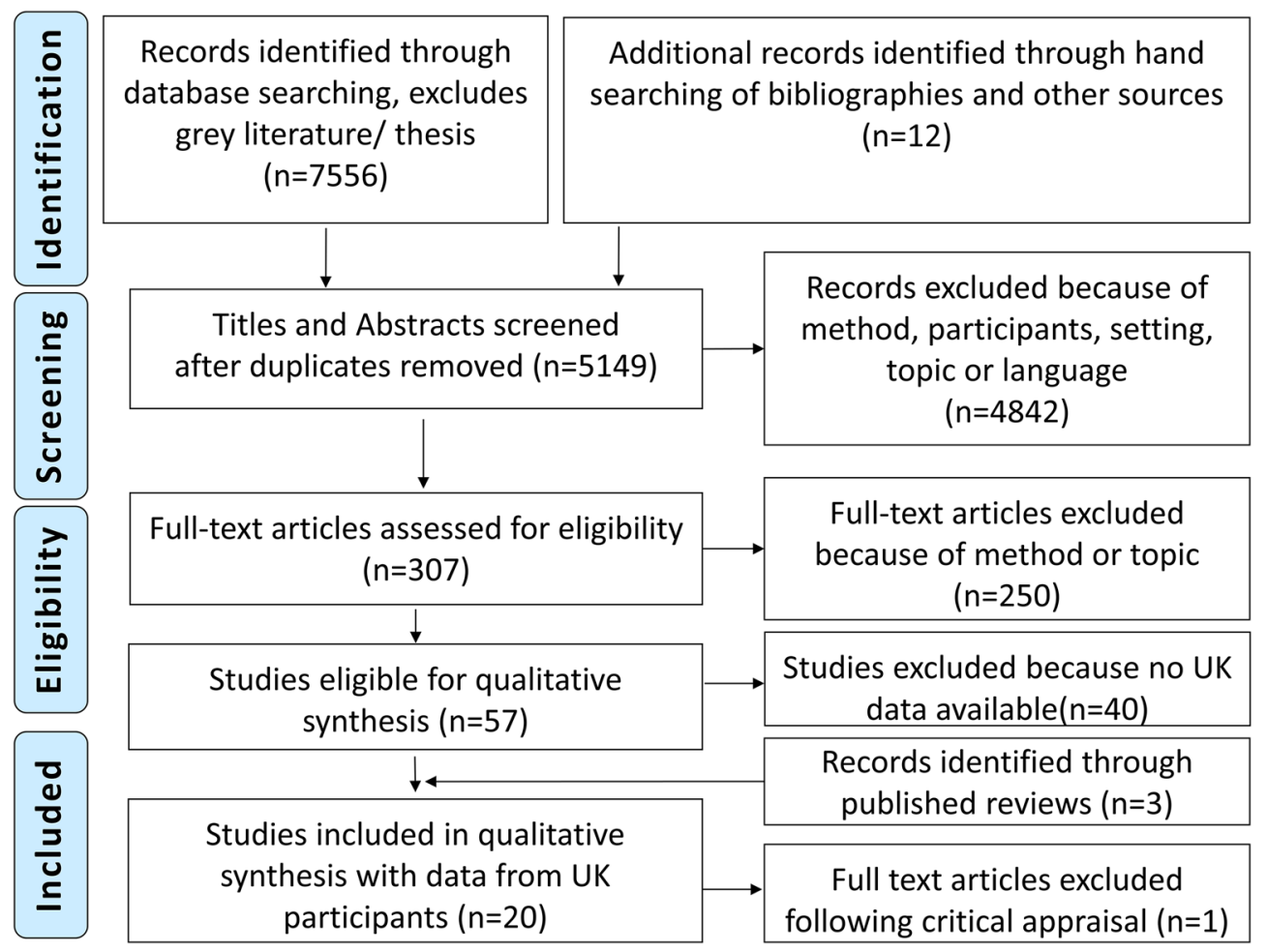

Fig. 2 Preferred Reporting Items for Systematic Reviews and Meta-Analysis (PRISMA) flowchart

\section{Data Synthesis}

Papers reporting data from the same research study were collated as one. None of the eligible studies reported views on AODs and non-insulin injectable medicines. Papers were separated into four research-focus groups, namely, oral GLDs (OGLDs), insulin, diabetes medicines (OGLDs and insulin) and polypharmacy/multimorbidity, using the chronological approach to form the synthesis [28]. For example, articles which only described participants' experiences with OGLDs were part of the first group and were synthesized chronologically. First- and second-order constructs (i.e. direct quotes from participants and interpretations of authors) were extracted by AP using a spreadsheet to manage the synthesis process. Second-order constructs retained the terminology of the authors who published the study to preserve the meaning and context of their findings. Themes were separated into two categories of views and experiences, namely, prior to and after initiation of a medication treatment, to identify changes in participants' views about their medicines and their medication-taking behavior over time. Themes also included passages related to quality of care and weight to identify whether these aspects influenced medicinetaking behavior, although these did not represent third-order constructs. The studies were then translated into each other, one by one, to form a reciprocal (i.e. similar findings) or refutational (i.e. contradictory findings) synthesis $[26,30]$. Briefly, the synthesis of the first two papers was compared with the third paper, and this process continued until all studies were translated into each other. This process was done separately for the "OGLD" and "insulin" groups. The findings from the "diabetes medicines" and "polypharmacy/multimorbidity" groups were then compared with each of the first two groups where relevant. In the process of comparing the studies against each other, explicit differences among the studies were noted (Table 1). Finally, a "line-of-argument" synthesis [26] was constructed by developing an overarching model that linked the 


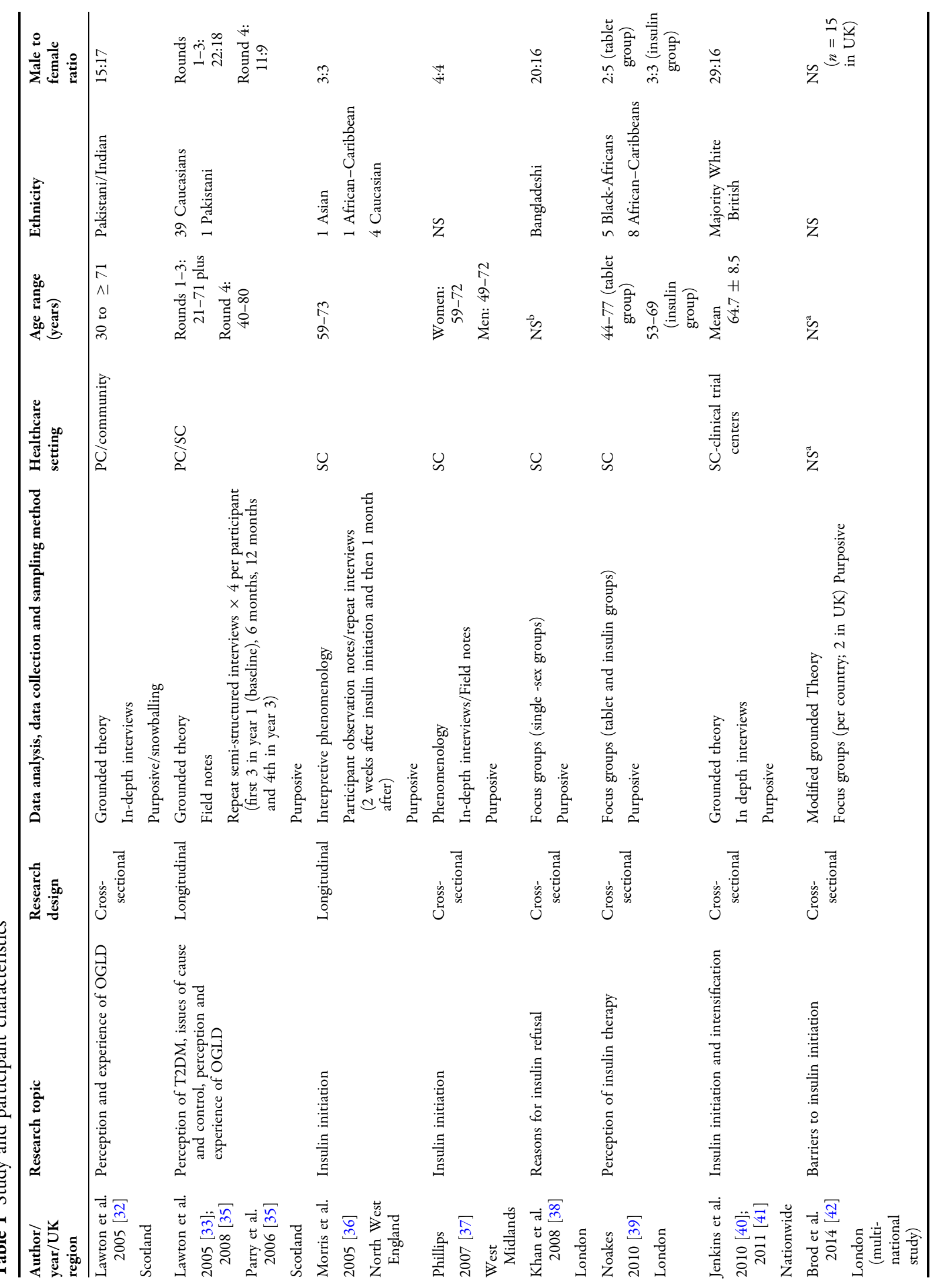




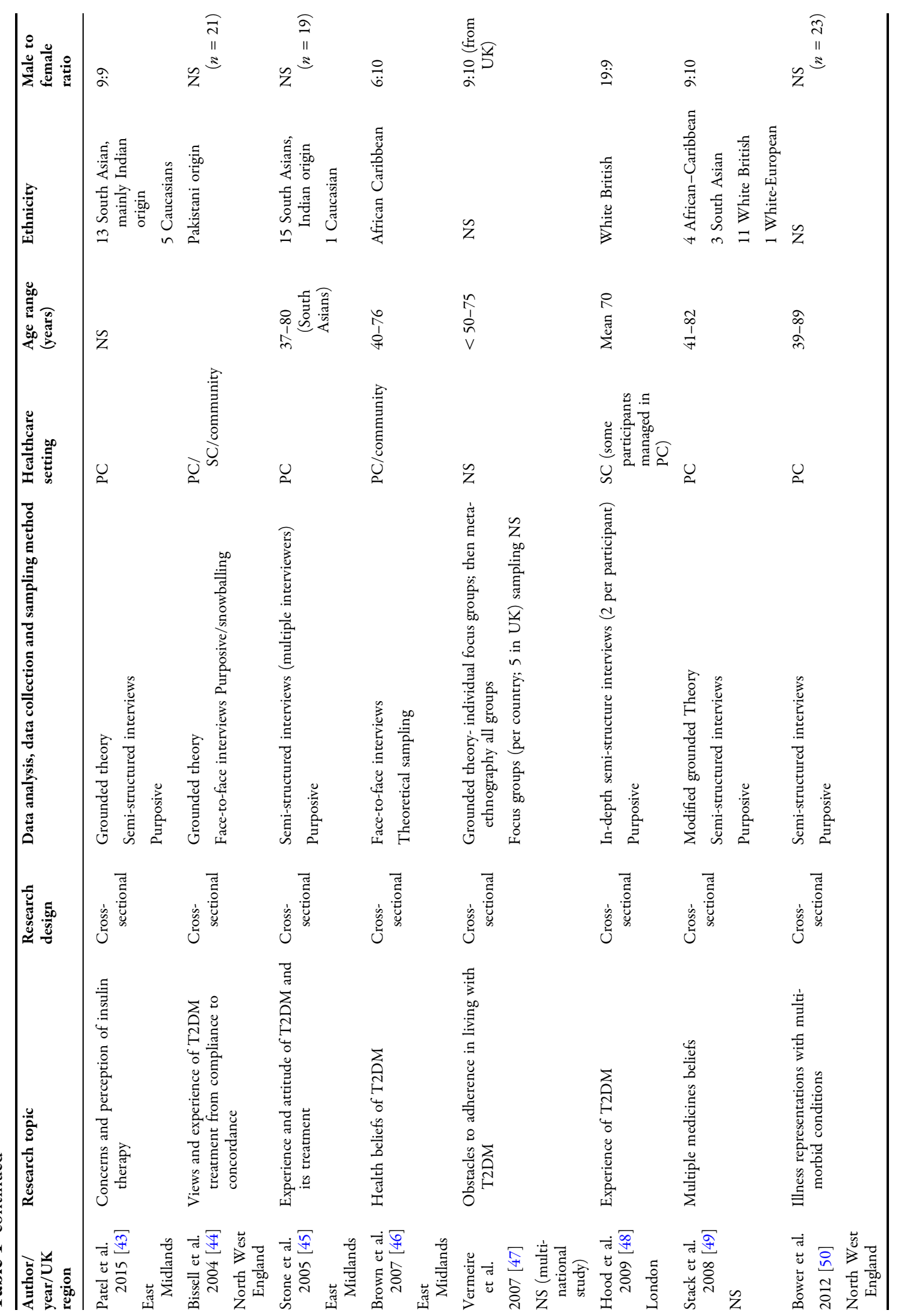




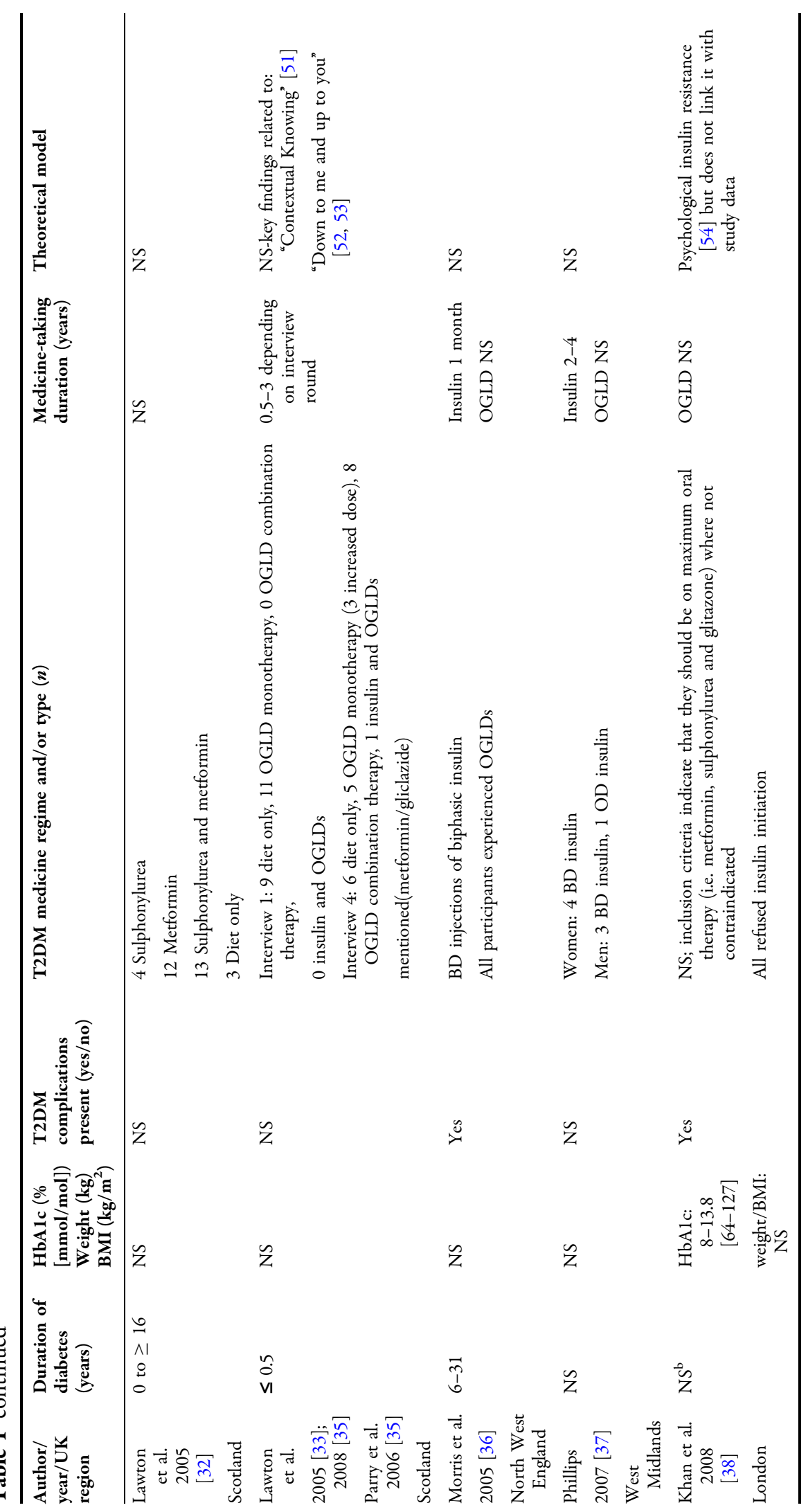




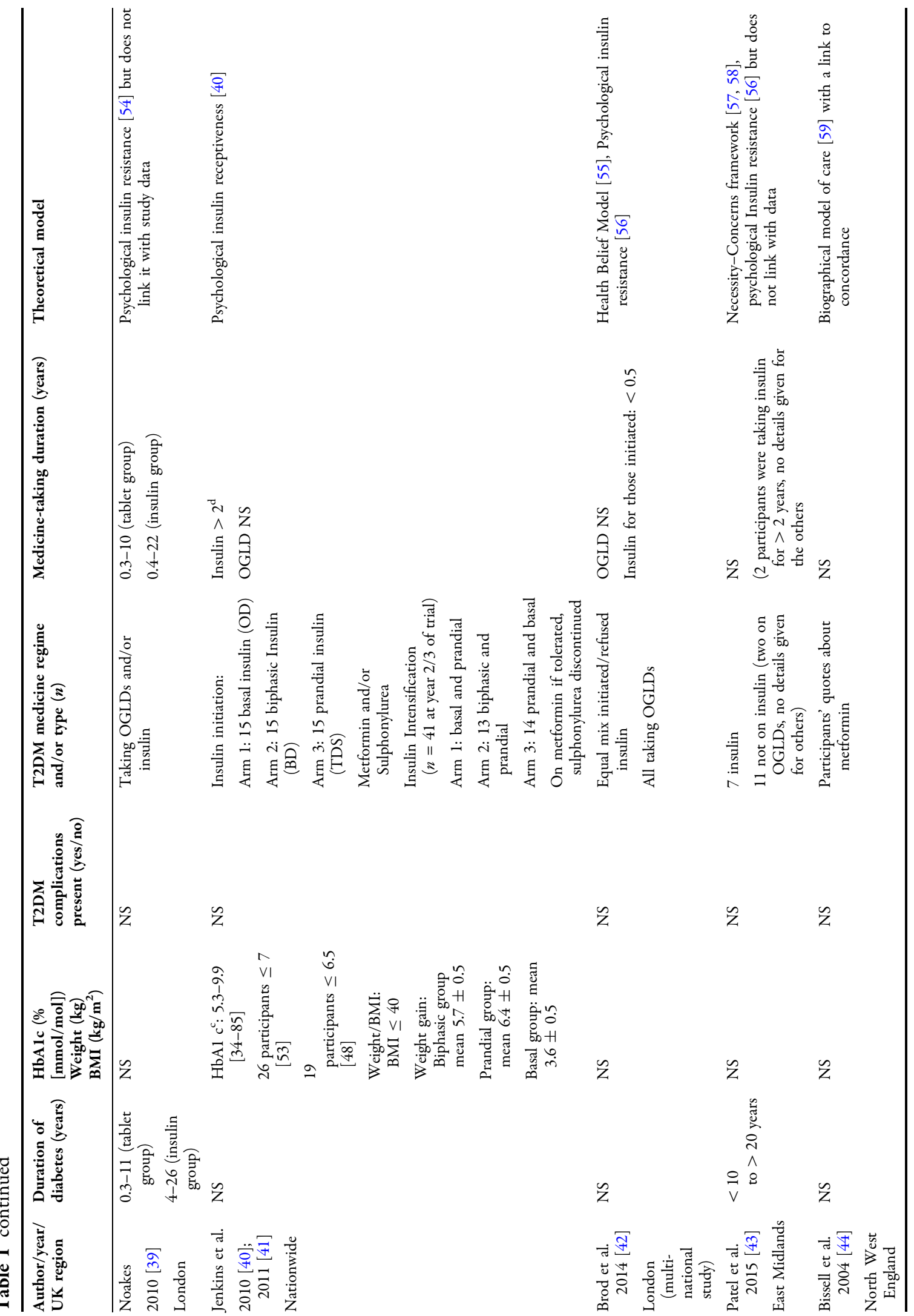




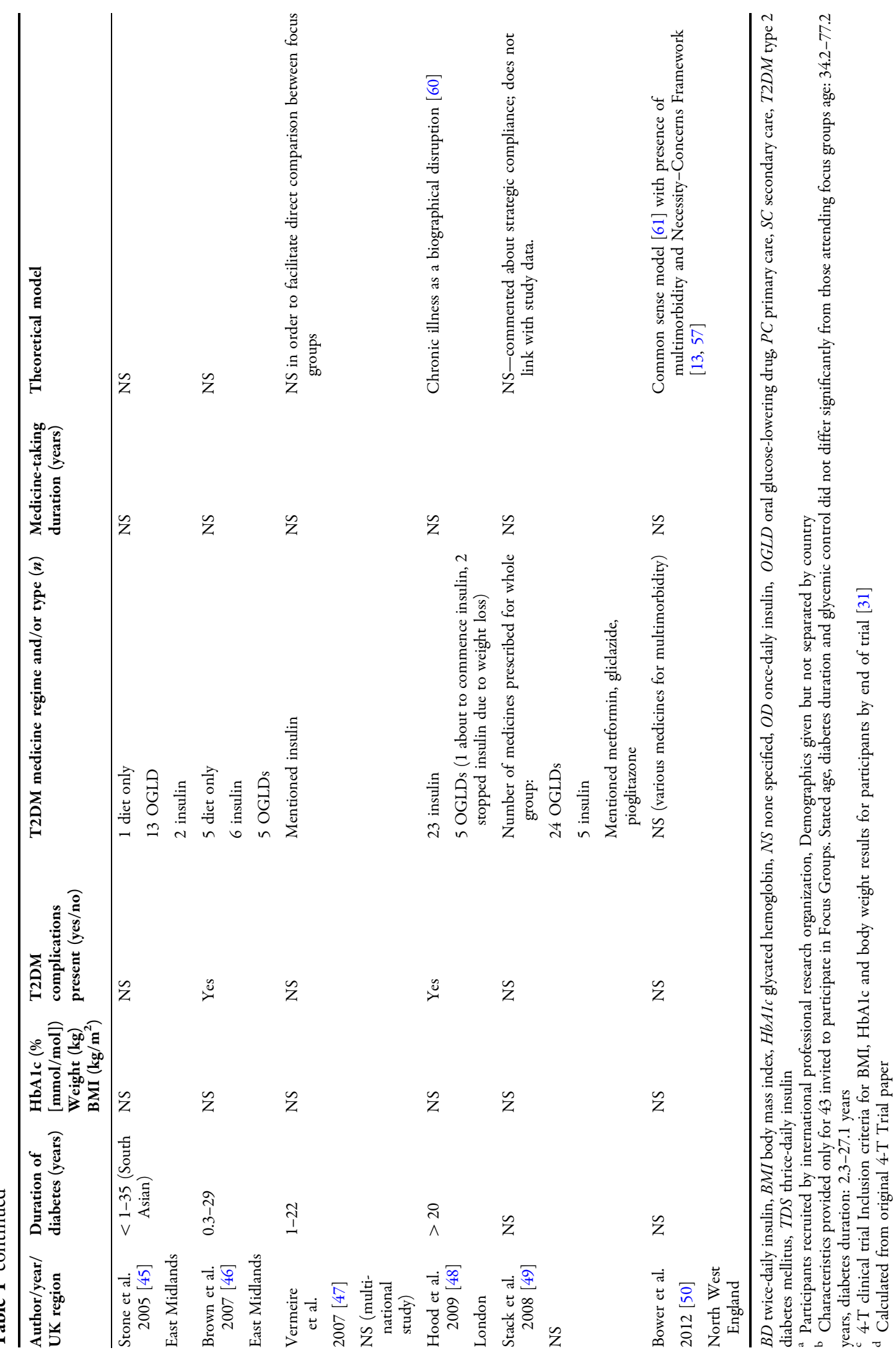


translations and authors' interpretations to address the aims of the review.

\section{RESULTS}

\section{Study and Participant Characteristics}

A total of 16 studies were reviewed (reported in 19 papers) (Table 1 ) using data from 360 individuals, mostly of Caucasian $(n=133)$ and South Asian origin $(n=122)$, all of whom were recruited from different UK regions, both in primary $(n=9)$ and secondary $(n=7)$ care. Participants (aged 21-89 years) had T2DM for a maximum of 35 years although their glycemic control and body mass index (or body weight) were rarely reported, except where details were extracted from a clinical trial [31] associated with one of the studies $[40,41]$.

Two studies employed a longitudinal study design to identify changes in participants' views $[34,36]$; however only one analyzed data longitudinally [34]. While the behavioral and social theories identified were linked to individuals' health-related behavior, the studies did not provide much detail beyond stating the theory applied.

\section{Medicine Types}

The studies examined in general various issues around the use of OGLDs and insulin, but none specifically addressed other injectable or OGLDs (i.e. glucogen-like peptide-1 [GLP-1] agonists, dipeptidyl peptidase 4 [DPP-4] inhibitors, or sodium/glucose cotransporter 2 [SGLT-2] inhibitors) or AODs (i.e. orlistat). One participant was taking insulin along with exenatide, a GLP1 analog; however, the focus of that study was solely on insulin [43]. Medication name or regime was rarely reported, except where participants' quotes indicated multiple use of diabetes and non-diabetes medicines or specified generic drug names.

Studies related to participants' views following the initiation of insulin therapy included those involving participants who took insulin for at least 1 month [36] as well as those in which the participants were taking insulin for more than 2 years [37, 40, 41]. Studies related to barriers and refusal to initiate insulin therapy included participants who had either refused insulin in the last 3-6 months $[38,42]$ or had started insulin within 6 months [42]. Two studies [39, 43], related to perceptions about insulin, included individuals who either were already taking insulin (0.4-22 years) or were insulin naïve, while only two studies specific to OGLD treatment specified treatment duration (0.3-10 years) [33-35, 39].

\section{Data Synthesis}

The reciprocal synthesis (Fig. 3) shows a timeline illustrating patients' emotions arising from the prospect of initiating T2DM medication, including their perceptions of T2DM and respective medicines and their expectations of these medicines, as well as how these related to outcomes such as patterns of medication-taking and lifestyle behavior. The line-of-argument synthesis (Fig. 4) demonstrates the key processes to understanding patients' journeys in medication management.

\section{Negative Emotional Impact}

Devastation, shock, anger and disappointment were the major emotions which appeared with the prospect of taking medicines [32, 34, 36, 37, 40, 48]. Starting OGLD therapy was linked to becoming a "sick person" [32, 34] and entering "a slippery slope" [34] leading to taking insulin, often associated as "the last resort" [38, 39, 43]. Patients referred to being "defeated" and letting themselves down by failing to self-manage their diabetes and diabetes treatment [34, 37, 39, 42]. Personal failure also emerged when patients were advised to start insulin therapy, mainly when initiation was imminent [37], and because they would be judged by others as a "bad diabetic" [48].

\section{My Diabetes is Serious}

Over time patients, particularly if symptomatic [48], rationalized that diabetes is a progressive 


\section{Moving from Diet Therapy to Tablets to Insulin for T2DM}

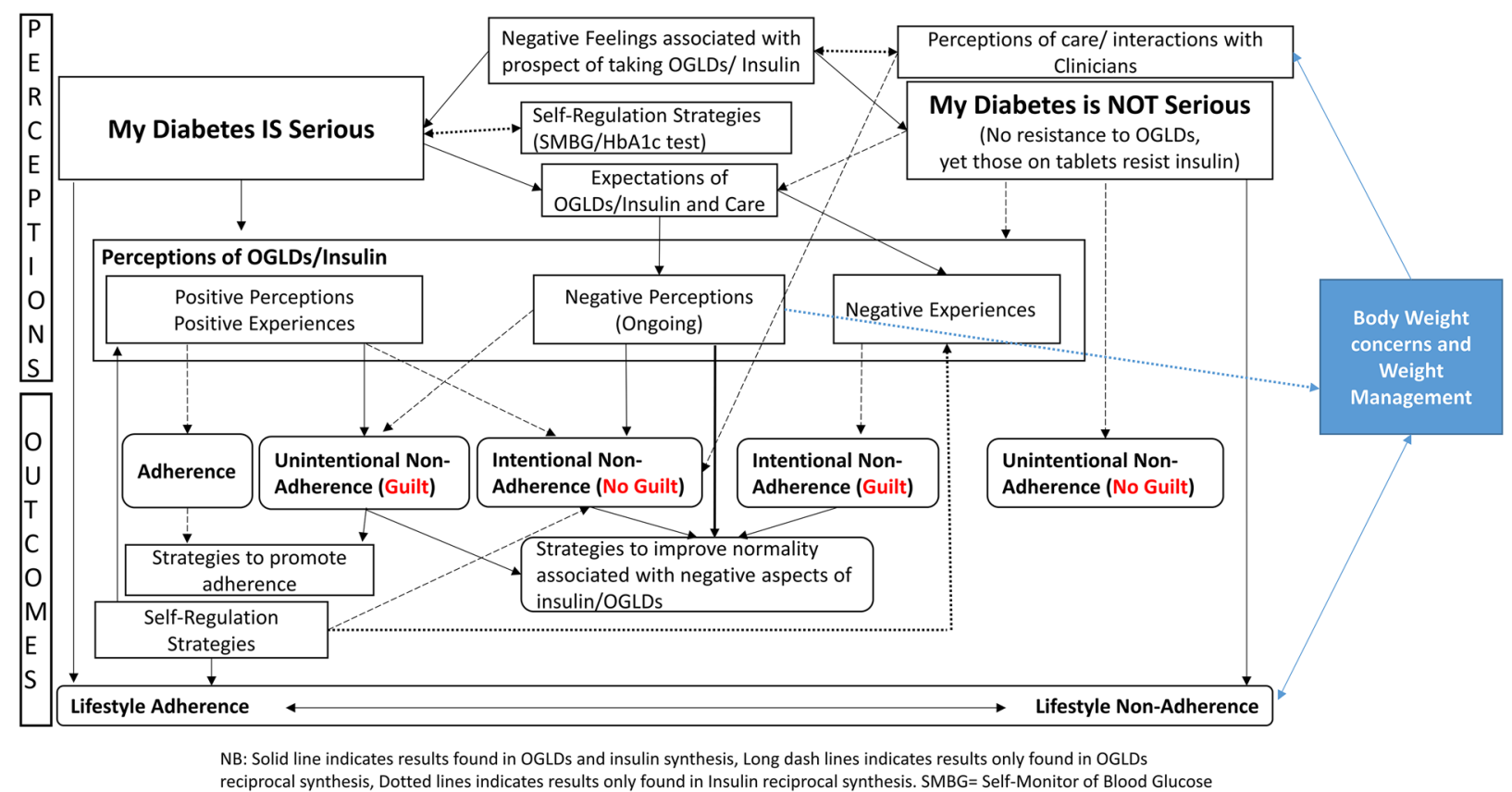

Fig. 3 Medicine map-reciprocal synthesis. OGLD Oral glucose-lowering drug, HbAIc glycated hemoglobin, T2DM type 2 diabetes mellitus

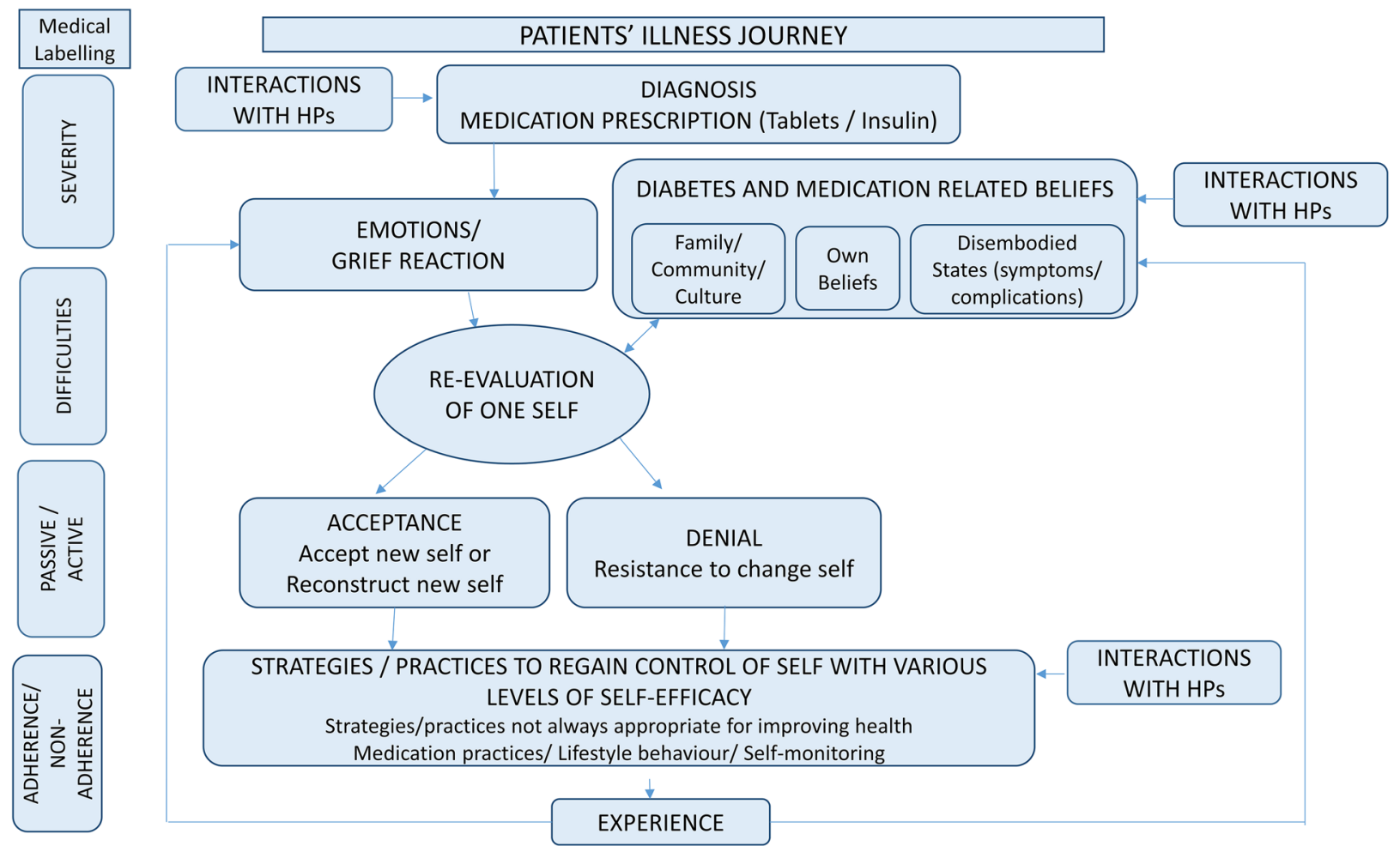

Fig. 4 Line-of-argument synthesis. HPs Health professionals 
disease [32, 34, 49], believing that lifestyle can cause it but cannot cure it [35], "...no matter how careful you are" [32]. This group of patients, many of whom were aware of T2DM and its treatment from family members [45], placed importance on the role of medicines in managing diabetes $[36,37,39,48,49]$. Once they had initiated medicines, they expressed the view that they would have to take them for the rest of their life $[32,49,50]$, otherwise, they would "risk dying" [32]. This view was reinforced by self-regulation strategies which supported the acceptance of new medication prescriptions (top box, Fig. 3). The combination of results from blood glucose testing and their own observations over time of an increase in the number of diabetes tablets and doses were good indicators of deteriorating diabetes despite adherence to treatment [40,43], justifying for some that eventual insulin treatment was an integral part of diabetes. Nonetheless, for others, blood glucose testing [34, 45] (bottom box, Fig. 3), over time, proved that medicines had helped with blood glucose control $[34,36,41,45]$ if they were asymptomatic or "unconvinced" of the medicine's effectiveness, reinforcing their perceptions and positive experiences. In contrast, some on insulin therapy felt frustrated when they could not see the results of their efforts to achieve good diabetes control [37].

\section{My Diabetes is Not Serious}

In our review this group of patients consists of those prescribed OGLDs but who had either no experience of taking insulin or were advised to take insulin but refused to do so [33, 35, 38, 39, 42-44]. These patients did not want to actively think about their diagnosis [34, 45], denying the possibility of future complications [46] or believing these are not imminent and believing that their diabetes is "insignificant" [33] if symptoms ceased after being prescribed OGLDs or if T2DM was managed with tablets [37, 38, 42, 43, 48]. Insulin was an indicator of the worse type of diabetes [37-39] and associated with more side effects than the tablets [39], and the reluctance to initiating insulin therapy was associated with negative stigma (Section Perceptions and Experiences of Medicines) and past medication experiences, particularly if OGLDs were perceived unsuccessful in diabetes management [38]. Additionally, Lawton et al. [33] suggested that the type and location of care can change an individual's perception of his/her diabetes, where care provided by the general practitioner is perceived as less serious than hospital care.

\section{Expectations of Medications and Care}

Key motivators for accepting diabetes medicines included instant success, specifically with an injectable treatment, and benefits of both weight loss and diabetes control [35, 43]. Generally, individuals wished to consult a healthcare profession who they considered to be an expert or trustworthy, an individual who they trusted would prescribe medications appropriately [32, 33, 39, 45], and they wished for continuity of care between healthcare services and health professionals (HPs) [37].

Patients' information needs were found to be high $[34,35,49,50]$, despite expecting an ongoing prescription [33, 34] and not questioning medication changes [34]. They preferred non-judgmental guidance [34] on alleviating negative medication experiences and managing missed doses and information that uses "layman's" language $[45,50]$. Specific to insulin, they wanted to know the advantages and disadvantages of taking insulin [37, 43, 48], what type and how many doses are required to control diabetes and if any changes are required in these $[36,39,41]$, how to inject insulin correctly and guidance on dietary changes [39]. They also wanted to be better informed about the need for their medicines, particularly if they hold negative views about them [49].

\section{Perceptions and Experiences of Medicines}

Patients' positive medication experiences reinforced positive perceptions that medications are beneficial, effective, relieve symptoms and preserve health [32, 34, 36, 37, 39, 41, 49]. When medication effects were seen over time [36, 41], 
some patients indicated that medicines were more effective than lifestyle measures $[34,35,49]$, prioritizing certain T2DM medicines over others [32, 49, 50] and reporting insulin being better than tablets [37, 39].

However, medications were unnatural $[32,34,36,46]$. Therefore, those taking multiple medicines (whether on complex diabetes and non-diabetes medication regimes) were worried these could counteract their individual effects [32] or "that's three lots attacking the kidney" [34], resulting in long-term health damage $[32,34,46]$. They wished to minimize the daily medication numbers or simplify the regime to help overcome their ongoing concerns and cope with the demands of self-managing diabetes [50].

Moreover, insulin was perceived negatively by all patients whether they refused it or not, with many expressing they would rather take more OGLDs than inject insulin [43]. Common worries were needle anxiety [36, 38-41, 48], fear of consequences/complications of permanently taking injections $[37,43]$, fear of weight gain or inability to lose weight $[38,42]$ and fear of hypoglycemia [37-39, 42]. Insulin was perceived as restricting and interfering with their lives [38], including daily and social activities and traveling [37-39, 42], and with increased dependence on others [38, 39]. Those participants who were experienced with insulin therapy reported that they had lost their identity and normality $[36,48]$, found it harder to selfmanage diabetes [37] and worried about injecting in public, particularly if they needed to inject with meals. Insulin was also perceived as a threat [36, 39, 42], often used by HPs to encourage patients to better control their diabetes. However, insulin perception transformed into "punishment" [37] for those starting insulin due to its association with negative stigma $[37,43]$ and the belief it was unjust [36], perhaps originated from the way it was introduced.

\section{Patterns of Medicine-Taking Behavior and Associated Strategies}

Overall, five adherence patterns were identified (Fig. 3). There were those who fully adhered to diabetes medicines and who strongly believed in the positive aspects of these medicines. However, they felt guilty when they unintentionally non-adhered to their medicines $[33,34,41,49]$ due to forgetfulness, broken routines, being asymptomatic and confusion when taking multiple medicines [34, 41]. Adherent and unintentional non-adherents adopted strategies to promote adherence, such as establishing routines that included identifying logistics of where and when to inject, using visual and family reminders, using medication boxes or carrying medicines with them or receiving group support $[34,37,41]$.

Conversely, there were some patients who unintentionally non-adhered to medicines due to forgetfulness, who did not appear to feel guilty about that behavior, perhaps due to lack of symptoms and their belief that diabetes is not a serious condition [33]. In those who exemplified intentional non-adherence, guilt was also rarely present [34]. Reasons for non-adherence included strong negative perceptions of their medication, such as insulin stigma [41], adverse effects [32, 33] and the medication being detrimental to health $[32,50]$. Strategies of intentional non-adherents included adjusting doses, delaying or omitting taking the medicines altogether [32, 34, 35, 41, 50], often manipulated by using self-monitoring of blood glucose and/or diet, because they believed that medicines work instantly by alleviating symptoms [32, 35]. HPs also indirectly influenced medication-taking behavior if they had in the past advised patients to adjust medicines; so in similar situations, patients were adjusting doses without seeking medical advice [32]. For those taking insulin, strategies included talking to friends and family about T2DM and treatment of hypoglycemia $[37,39]$ by regularly referring to written material and actively seeking further information on diabetes treatments [37], often encouraged by their family [36, 37]. They manipulated their diet by eating more often to avoid feeling weak, which according to the authors was unlikely to be linked with low blood glucose [46], or restricted social activities such as eating out to avoid injecting in public [41]. 


\section{Lifestyle Behavior and Weight Management}

Great importance to lifestyle measures was given by those who perceived their diabetes as serious and who had converted to insulin [35], by strictly following a healthy eating plan $[37,39]$ or using a moderate approach to eating "... a little bit of what you fancy" [48]. In contrast, others could not identify if any changes to their lifestyle had an impact on diabetes control and were uncertain of their diet's effectiveness [45], struggling to keep up with the diet and physical activity [33, 35, 37, 44]. Yet others indicated that the lifestyle and medication are two alternative ways in which they could self-manage diabetes, suggesting that once you take medicines they could eat what they want $[35,39,48]$, particularly when on insulin [39].

Concerns of weight gain were apparent, but these were not linked to diabetes medicines, except when fear of weight gain was associated to the refusal to initiate insulin therapy $[38,42,46]$. Hence, weight was related to lifestyle measures, even though many patients were "naughty" and "cheating" [33] or were unsure how to reduce calories [39]; they felt misunderstood by HPs in relation to the difficulties they faced $[44,47]$ with following the recommended diet. Conversely, others suggested that they would lose weight if they were to avoid taking medicines [35, 49], although not all believed that it would be diabetes medicines [49].

\section{Line-of-Argument Synthesis}

Patients' journeys started either at the time of diagnosis and/or at the time of medication prescription, both creating grief reactions. As patients progressed from diet to tablets to insulin, their emotional reactions were progressively stronger and impacted upon the way they coped. However, perceptions of diabetes severity appeared to change over time and were influenced by their community and family experiences [36, 38, 39, 43, 45], the presence/ lack of diabetes symptoms and complications $[33,35,37,43,45-48]$ and their own medication beliefs. Taken together, beliefs and emotions reinforced an evaluation of oneself, leading to either accepting or denying the "altered self-image" [36]. Generally, acceptance to change meant that medicines were accepted as part of the successful management of diabetes. However, resistance to change did not necessarily mean resistance to taking medicines.

Medication-taking and lifestyle behavior coupled with self-regulation strategies were all tactics patients engaged to regain self-control. These were often associated with patients' treatment adherence or non-adherence $[34,35,41,49]$ and to being passive or active $[34,36,43]$ in self-managing diabetes, terms commonly used in clinical research and practice. However, for patients these strategies are rational decisions/actions enabling them to live as normally as possible and to minimize the impact of their diabetes and medicines in everyday life.

Patients were committed to taking medicines $[34,37]$ with a "sense of growing confidence" [36] and were making conscious and deliberate "effort" $[37,41]$ to find out about diabetes and adapt their daily practices to fit medication, with some "requesting" or "negotiating" their new regime [34, 41]. Still others reported feeling "powerless" [36], conveying "worry" [39] because they had "tried hard" [37] but had been unable to make successful changes. Hence, the experience of successful and unsuccessful practices reinforces or undermines patients' T2DM treatment beliefs and leads yet again to a re-evaluation of self.

\section{DISCUSSION}

This synthesis identified that patients associate T2DM severity with both their treatment (lifestyle vs. medicine) and prescribed medicine (tablet vs. insulin). The results suggest that the experience of starting or changing to a new diabetes medication results in a self-re-evaluation that the patient can either accept or deny. The re-evaluation of self is an endless cyclical process depending on the daily positive and negative emotional and cognitive experiences of self-managing diabetes alongside interactions 
with HPs. Grieving takes time [62], and the revival of grief reactions during changes in medication have been referred to as chronic sorrow-i.e. the reactions associated with repeated losses of independence and control and loss of identity as a healthy person, generating a disparity between the current reality and the desired reality [63]. Different levels of resistance and acceptance of diabetes identity and selfmanagement have also been found in other studies [64, 65].

However, all patients were engaged in strategies to enable them to regain control of their life, as often seen in patients with chronic conditions [66]. Confidence in taking medicines (i.e. self-efficacy) predicts treatment adherence [17], but the patients in this review had different levels of self-efficacy and coping efficacy. Those who self-managed well were those who were confidently able to modify daily routines to fit medication regimes, overcoming such challenges as polypharmacy, inconvenient schedules and lack of reminders. Nevertheless, intentional and unintentional non-adherence was more common than medication adherence, reflecting findings from other 'adherence' systematic reviews $[3,4]$.

Seemingly, accepting diabetes as a serious disease, and therefore medicines as necessary, and having high self- and coping-efficacy, along with positive experiences following the initiation of a new treatment are important for medication adherence. However, when individuals do accept their medicines, they seem to have less faith in lifestyle changes as a strategy for self-managing diabetes, coinciding with the findings of a longitudinal study showing that lifestyle behaviors diminished over time in people with T2DM [67]. However, commitment to lifestyle measures could be associated with individuals' change of views and attitudes towards their diabetes treatment, including medications.

The findings from this review have potential implications for both policy and practice. Informing patients of the T2DM medication treatments available and the inevitable progression from oral to injectable medicines could increase awareness and allow time for grieving so that when eventually a prescription is required, these medicines are more easily accepted. Moreover, if patients' expectations of new diabetes medicines are positively reinforced, i.e. good results, this could lead to a reinforcement of positive perceptions and acceptance of the medicines. A focus by HPs on areas of medication concerns both prior and during treatment is a priority for helping patients to minimize their concerns and accept medicines in a way that promotes better adherence. Interventions could be designed to promote treatment adherence by taking into account emotional and cognitive factors and building confidence in daily practices and social and family support mechanisms.

In addition, the patients in this review associated weight loss with making lifestyle changes. However, their perceptions of weight loss as an effective strategy to manage their diabetes varied, a finding that conflicts with current medical evidence $[68,69]$. It is unclear whether patients were aware of the effects of the different medicines on body weight, despite many of them having an undesirable effect [69]. Most patients appear to trust and accept doctors to make decisions about their medicines. However, if they are not involved in the decisionmaking process on medication treatment, it is uncertain whether they are likely to choose a medication based on its ability to support weight loss or control [23], and whether knowing the impact of the medicine on their body weight will affect adherence levels.

The synthesis model also has implications for theory, proving that no single theory can be used to fully illuminate medicine-taking behavior by people with T2DM. Instead, various theories can be applied, a number of which are shown in Table 1 . These include, in no particular order, the model of illness representations [61] where emotional (guilt and grief reaction) and cognitive factors (illness and medicationrelated beliefs, perceived self- and coping-efficacy) are involved in changing the view of oneself and their practices. In line with the Necessity-Concerns framework [13, 57], patients showed they have ongoing concerns about their medicines, and these concerns coupled with their perceived need of their diabetes medicines could influence their 
medication adherence. Additionally, as evident from the patients' accounts and authors' interpretations, patients and HPs portray different explanatory models of illness [59], which leads to the different medical labeling in Fig. 4. For example, what HPs see as non-adherence, patients see as rational ways of taking control of their life. Thus, such discrepancy in illness models potentially can impact adherence. Finally, the starting a new T2DM medicine, and not just the onset of chronic illness, indicates a biographical disruption [60]. The authors of some studies have described psychological insulin resistance, whereas Jenkins et al. [40] described psychological receptiveness. However, these resistance and receptiveness concepts relate to the concepts of medication denial and acceptance based on patients' perception of diabetes seriousness. Over time, insulin-experienced patients, i.e. those who have taken insulin for longer than 2 years, were more accepting of this treatment.

\section{Strengths and Limitations}

The review's strength is reflected by the systematic identification of papers using both broad and specific search strategies and multiple databases. Its rigor is enhanced by the inclusion of high-quality papers based on the CASP score following critical appraisal by two of the research team. The transparency and trustworthiness of the findings were ascertained by detailed discussions among the research team about the interpretation of the findings. However the transferability of findings and conceptual models to patients from other countries is limited due to our restriction on language and focus on medication experiences from a selected group of UK participants who are medically/ pharmacologically treated and do not pay for their prescriptions.

The intention of the synthesis was to retain a rich context of data by looking systematically at the influences of various contextual factors on medication-taking behavior, such as socio-economic status, diabetes control, body weight, disease and treatment duration, treatment type and use of healthcare services, as seen elsewhere
$[19,24,70]$. However, this was difficult as the authors of many studies did not provide adequate descriptions of context and the impact of context on their findings (Table 1). We believe such information would be useful to better describe the medication adherence phenomenon. Only a few papers provided rich and insightful data to fully appreciate patients' experiences and practices with diabetes medicines. While there were only two longitudinal studies, most studies were based on peoples' memories of past experiences and their views after medication changes had occurred. The synthesis related to OGLDs was based on two studies, which were mainly conducted by the same group of authors. Furthermore, the process of synthesizing is inherently interpretive, so other reviewers may produce difference conceptual frameworks. Nonetheless, 19 papers provided sufficient data to reach a "line-of-argument" resonating findings from other published reviews $[14,17,20,22,24,71]$. This suggests that our findings are triangulated and credible.

\section{CONCLUSION}

This meta-ethnographic review provides new insights into T2DM patient' reasons for poor adherence and identifies specific practical issues which can help in the development of patientcentered interventions. The models demonstrate how the theories could be interlinked and applied to future research. Further research is needed to develop informed patient-centered approaches to improving treatment adherence among people with T2DM. Research should focus on understanding how patients' views of their medicines change over time based on longitudinal studies and how their experiences have an impact on adherence by investigating factors such as glycemic control and body weight changes and type of treatment, including other injectable medicines. Without knowing what causes changes in peoples' perceptions and behaviors there will always be uncertainty as to which interventions can help support patients to improve their health and quality of life. 


\section{ACKNOWLEDGEMENTS}

Funding. This work was funded through Diabetes UK research fellowship scheme for nurses, midwives and allied health professionals award to Aikaterini Psarou (Grant number 10/0004124). This paper represent the authors' views and not the views of the funding source. The article processing charges were funded by the University of Liverpool.

Authorship. All named authors meet the International Committee of Medical Journal Editors (ICMJE) criteria for authorship for this article, take responsibility for the integrity of the work as a whole, and have given their approval for this version to be published.

Authorship Contributions. Aikaterini Psarou designed the study, performed the data analysis, interpreted the results, wrote the manuscript and approved the final version. Helen Cooper contributed to the design and data analysis, as reported in the article, reviewed/edited the manuscript and gave final approval. John P. H. Wilding contributed to the design, reviewed/edited the manuscript and gave final approval.

Disclosures. Aikaterini Psarou, Helen Cooper and John P.H. Wilding have nothing to disclose.

Compliance with Ethics Guidelines. The article is based on previously conducted studies and does not involve any new studies of human or animal subjects performed by any of the authors.

Data Availability. Data sharing is not applicable to this article as no datasets were generated or analyzed during the current study.

Open Access. This article is distributed under the terms of the Creative Commons Attribution-NonCommercial 4.0 International License (http://creativecommons.org/licenses/ by-nc/4.0/), which permits any noncommercial use, distribution, and reproduction in any medium, provided you give appropriate credit to the original author(s) and the source, provide a link to the Creative Commons license, and indicate if changes were made.

\section{REFERENCES}

1. Diabetes UK. Type 2 diabetes and obesity: a heavy burden. London: Diabetes UK; 2005.

2. Philippe J, Raccah D. Treating type 2 diabetes: how safe are current therapeutic agents? Int J Clin Pract. 2009;63(2):321-32.

3. Cramer JA. A systematic review of adherence with medications for diabetes. Diabetes Care. 2004;27(5):1218-24. https://doi.org/10.2337/ diacare.27.5.1218.

4. Krass I, Schieback P, Dhippayom T. Adherence to diabetes medication: a systematic review. Diabet Med. 2015;32(6):725-37.

5. Rucker D, Padwal R, Li SK, Curioni C, Lau DC. Long term pharmacotherapy for obesity and overweight: updated meta-analysis. BMJ. 2007;335(7631):1194-9.

6. Haynes RB, Ackloo E, Sahota N, McDonald HP, Yao $\mathrm{X}$. Interventions for enhancing medication adherence. Cochrane Database Syst Rev. 2008;(2):CD000011. https://doi.org/10.1002/ 14651858.CD000011.pub3.

7. Vermeire EI, Wens J, Van Royen P, Biot Y, Hearnshaw $\mathrm{H}$, Lindenmeyer A. Interventions for improving adherence to treatment recommendations in people with type 2 diabetes mellitus. Cochrane Database Syst Rev. 2005;(2):CD003638. https://doi. org/10.1002/14651858.CD003638.pub2.

8. Sapkota S, Brien JA, Greenfield J, Aslani P. A systematic review of interventions addressing adherence to anti-diabetic medications in patients with type 2 diabetes-impact on adherence. PLoS One. 2015;10(2):e0118296.

9. Steiner JF, Earnest MA. The language of medicationtaking. Ann Intern Med. 2000;132(11):926-30.

10. Hearnshaw H, Lindenmeyer A. What do we mean by adherence to treatment and advice for living with diabetes? A review of the literature on definitions and measurements. Diabet Med. 2006;23(7):720-8.

11. Blackburn DF, Swidrovich J, Lemstra M. Non-adherence in type 2 diabetes: practical considerations 
for interpreting the literature. Patient Prefer Adherence. 2013;7:183.

12. Vermeire E, Hearnshaw H, Van Royen P, Denekens J. Patient adherence to treatment: three decades of research. A comprehensive review. J Clin Pharm Ther. 2001;26(5):331-42.

13. Horne R, Weinman J. Patients' beliefs about prescribed medicines and their role in adherence to treatment in chronic physical illness. J Psychosom Res. 1999;47(6):555-67.

14. Campbell R, Pound P, Pope C, Britten N, Pill R, Morgan M, Donovan J. Evaluating meta-ethnography: a synthesis of qualitative research on lay experiences of diabetes and diabetes care. Soc Sci Med. 2003;56(4):671-84.

15. Gomersall T, Madill A, Summers LK. A metasynthesis of the self-management of type 2 diabetes. Qual Health Res. 2011;21(6):853-71.

16. Nam S, Chesla C, Stotts NA, Kroon L, Janson SL. Barriers to diabetes management: patient and provider factors. Diabetes Res Clin Pract. 2011;93(1):1-9. https://doi.org/10.1016/j.diabres. 2011.02.002.

17. Gherman A, Schnur J, Montgomery G, Sassu R, Veresiu I, David D. How are adherent people more likely to think? A meta-analysis of health beliefs and diabetes self-care. Diabetes Educ. 2011;37(3):392-408.

18. Odegard PS, Capoccia K. Medication taking and diabetes. Diabetes Educ. 2007;33(6):1014-29.

19. Peeters B, Van Tongelen I, Boussery K, Mehuys E, Remon JP, Willems S. Factors associated with medication adherence to oral hypoglycaemic agents in different ethnic groups suffering from type 2 diabetes: a systematic literature review and suggestions for further research. Diabet Med. 2011;28(3):262-75.

20. Majeed-Ariss R, Jackson C, Knapp P, Cheater FM. A systematic review of research into black and ethnic minority patients' views on self-management of type 2 diabetes. Health Expect. 2015;18(5):625-42.

21. Wang HF, Yeh MC. Psychological resistance to insulin therapy in adults with type 2 diabetes: mixed-method systematic review. J Adv Nurs. 2012;68(4):743-57.

22. Polinski JM, Smith BF, Curtis BH, Seeger JD, Choudhry NK, Connolly JG, Shrank WH. Barriers to insulin progression among patients with type 2 diabetes: a systematic review. Diabetes Educ. 2013;39(1):53-65.
23. Purnell TS, Joy S, Little E, Bridges JF, Maruthur N. Patient preferences for noninsulin diabetes medications: a systematic review. Diabetes Care. 2014;37(7):2055-62. https://doi.org/10.2337/dc132527.

24. Brundisini F, Vanstone M, Hulan D, DeJean D, Giacomini M. Type 2 diabetes patients' and providers' differing perspectives on medication nonadherence: a qualitative meta-synthesis. BMC Health Serv Res. 2015;15(1):516.

25. Garrofe BC, Bjornberg A, Phang AY. Euro diabetes index 2014 report. 2014. Available from: https:// old.healthpowerhouse.com/publications/eurodiabetes-index-2014/.

26. Noblit GW, Hare RD, Hare RD. Meta-ethnography: synthesizing qualitative studies. Thousand Oaks: Sage; 1988.

27. Britten N, Campbell R, Pope C, Donovan J, Morgan M, Pill R. Using meta ethnography to synthesise qualitative research: a worked example. J Health Serv Res Policy. 2002;7(4):209-15.

28. Pound P, Britten N, Morgan M, Yardley L, Pope C, Daker-White G, Campbell R. Resisting medicines: a synthesis of qualitative studies of medicine taking. Soc Sci Med. 2005;61(1):133-55.

29. CASP UK. CASP qualitative research checklist. 2010. Available at: http://www.casp-uk.net/checklists. Accessed 1 Apr 2014.

30. Campbell R, Pound P, Morgan M, Daker-White G, Britten N, Pill R, Yardley L, Pope C, Donovan J. Evaluating meta ethnography: systematic analysis and synthesis of qualitative research. Health Technol Assess. 2012;15:43. https://doi.org/10.3310/ hta15430.

31. Holman RR, Farmer AJ, Davies MJ, Levy JC, Darbyshire JL, Keenan JF, Paul SK. Three-year efficacy of complex insulin regimens in type 2 diabetes. N Engl J Med. 2009;361(18):1736-47.

32. Lawton J, Ahmad N, Hallowell N, Hanna L, Douglas M. Perceptions and experiences of taking oral hypoglycaemic agents among people of Pakistani and Indian origin: qualitative study. BMJ. 2005;330(7502):1247.

33. Lawton J, Peel E, Parry O, Araoz G, Douglas M. Lay perceptions of type 2 diabetes in Scotland: bringing health services back in. Social Sci Med. 2005;60(7):1423-35.

34. Lawton J, Peel E, Parry O, Douglas M. Patients' perceptions and experiences of taking oral glucoselowering agents: a longitudinal qualitative study. Diabet Med. 2008;25(4):491-5. 
35. Parry O, Peel E, Douglas M, Lawton J. Issues of cause and control in patient accounts of Type 2 diabetes. Health Educ Res. 2005;21(1):97-107.

36. Morris JE, Povey RC, Street CG. Experiences of people with type 2 diabetes who have changed from oral medication to self-administered insulin injections. Pract Diabetes. 2005;22(7):239-43.

37. Phillips A. Experiences of patients with type 2 diabetes starting insulin therapy. Nurs Stand. 2007;21(23):35-41.

38. Khan H, Lasker SS, Chowdhury TA. Prevalence and reasons for insulin refusal in Bangladeshi patients with poorly controlled Type 2 diabetes in East London. Diabet Med. 2008;25(9):1108-11.

39. Noakes H. Perceptions of black African and AfricanCaribbean people regarding insulin. J Diabetes Nurs. 2010;14(4):148-56.

40. Jenkins N, Hallowell N, Farmer AJ, Holman RR, Lawton J. Initiating insulin as part of the treating to target in type 2 diabetes (4-T) trial: an interview study of patients' and health professionals' experiences. Diabetes Care. 2010;33(10):2178-80.

41. Jenkins N, Hallowell N, Farmer AJ, Holman RR, Lawton J. Participants' experiences of intensifying insulin therapy during the treating to target in type 2 diabetes (4-T) trial: qualitative interview study. Diabet Med. 2011;28(5):543-8.

42. Brod M, Alolga SL, Meneghini L. Barriers to initiating insulin in type 2 diabetes patients: development of a new patient education tool to address myths, misconceptions and clinical realities. Patient. 2014;7(4):437-50.

43. Patel N, Stone MA, McDonough C, Davies MJ, Khunti K, Eborall H. Concerns and perceptions about necessity in relation to insulin therapy in an ethnically diverse UK population with type 2 diabetes: a qualitative study focusing mainly on people of South Asian origin. Diabet Med. 2015;32(5):635-44.

44. Bissell P, May CR, Noyce PR. From compliance to concordance: barriers to accomplishing a re-framed model of health care interactions. Soc Sci Med. 2004;58(4):851-62.

45. Stone M, Pound E, Pancholi A, Farooqi A, Khunti K. Empowering patients with diabetes: a qualitative primary care study focusing on South Asians in Leicester, UK. Fam Pract. 2005;22(6):647-52.

46. Brown K, Avis M, Hubbard M. Health beliefs of African-Caribbean people with type 2 diabetes: a qualitative study. $\mathrm{Br} \mathrm{J}$ Gen Pract. 2007;57(539):461-9.
47. Vermeire E, Hearnshaw H, Rätsep A, Levasseur G, Petek D, van Dam H, van der Horst F, VinterRepalust N, Wens J, Dale J, Van Royen P. Obstacles to adherence in living with type-2 diabetes: an international qualitative study using meta-ethnography (EUROBSTACLE). Primary Care Diabetes. 2007;1(1):25-33.

48. Hood G, Huber J, Gustaffson U, Scambler S, Asimakopoulou K. 'With age comes wisdom almost always too late': older adults' experiences of T2DM. Eur Diabetes Nurs. 2009;6(1):23-8.

49. Stack RJ, Elliott RA, Noyce PR, Bundy C. A qualitative exploration of multiple medicines beliefs in comorbid diabetes and cardiovascular disease. Diabet Med. 2008;25(10):1204-10.

50. Bower P, Harkness E, Macdonald W, Coventry P, Bundy C, Moss-Morris R. Illness representations in patients with multimorbid long-term conditions: qualitative study. Psychol Health. 2012;27(10):1211-26.

51. Gordon DR. Embodying illness, embodying cancer. Cult Med Psychiatry. 1990;14(2):275-97.

52. Cohen MZ, Tripp-Reimer T, Smith C, Sorofman B, Lively S. Explanatory models of diabetes: patient practitioner variation. Soc Sci Med. 1994;38(1):59-66.

53. Frank AW. The rhetoric of self-change: illness experience as narrative. Sociol Q. 1993;34(1):39-52.

54. Polonsky WH, Jackson RA. What's so tough about taking insulin? Addressing the problem of psychological insulin resistance in type 2 diabetes. Clin Diabetes. 2004;22(3):147-50.

55. Rosenstock IM, Strecher VJ, Becker MH. Social learning theory and the health belief model. Health Educ Q. 1988;15(2):175-83.

56. Polonsky WH, Fisher L, Guzman S, Villa-Caballero L, Edelman SV. Psychological insulin resistance in patients with type 2 diabetes: the scope of the problem. Diabetes Care. 2005;28(10):2543-5.

57. Horne R, Weinman J, Hankins M. The beliefs about medicines questionnaire: the development and evaluation of a new method for assessing the cognitive representation of medication. Psychol Health. 1999;14(1):1-24.

58. Aikens JE, Nease DE, Nau DP, Klinkman MS, Schwenk TL. Adherence to maintenance-phase antidepressant medication as a function of patient beliefs about medication. Ann Family Med. $2005 ; 3(1): 23-30$. 
59. Kleinman A, Eisenberg L, Good B. Culture, illness, and care: clinical lessons from anthropologic and cross-cultural research. Ann Intern Med. 1978;88(2):251-8.

60. Bury M. Chronic illness as biographical disruption. Sociol Health Illn. 1982;4(2):167-82.

61. Leventhal H, Meyer D, Nerenz D. The common sense representation of illness danger. In: Rachman S, editor. Contributions to medical psychology, vol. 2. New York: Pergamon Press; 1980. p. 7-30.

62. Brown SA. Diabetes and grief. Diabetes Educ. 1985;11(2):53-7.

63. Ahlström G. Experiences of loss and chronic sorrow in persons with severe chronic illness. J Clin Nurs. 2007;16(3a):76-83.

64. Savoca MR, Miller CK, Quandt SA. Profiles of people with type 2 diabetes mellitus: the extremes of glycemic control. Soc Sci Med. 2004;58(12):2655-66.

65. Ockleford E, Shaw RL, Willars J, Dixon-Woods M. Education and self-management for people newly diagnosed with type 2 diabetes: a qualitative study of patients' views. Chronic Illness. 2008;4(1):28-37.
66. Haslbeck JW, Schaeffer D. Routines in medication management: the perspective of people with chronic conditions. Chronic Illness. 2009;5(3):184-96. https://doi.org/10.1177/ 1742395309339873.

67. Nothwehr F, Stump T. Health-promoting behaviors among adults with type 2 diabetes: findings from the Health and Retirement Study. Prev Med. 2000;30(5):407-14.

68. Lau DC. Diabetes and weight management. Primary Care Diabetes. 2010;1(4):S24-30.

69. Ross SA, Dzida G, Vora J, Khunti K, Kaiser M, Ligthelm RJ. Impact of weight gain on outcomes in type 2 diabetes. Curr Med Res Opin. 2011;27(7):1431-8.

70. Davies MJ, Gagliardino JJ, Gray LJ, Khunti K, Mohan V, Hughes R. Real-world factors affecting adherence to insulin therapy in patients with Type 1 or Type 2 diabetes mellitus: a systematic review. Diabet Med. 2013;30(5):512-24.

71. McSharry J, McGowan L, Farmer AJ, French DP. Perceptions and experiences of taking oral medications for the treatment of Type 2 diabetes mellitus: a systematic review and meta-synthesis of qualitative studies. Diabet Med. 2016;33(10):1330-8. 